\title{
CONSTRUCIONISMO SOCIAL E TRABALHO COMUNITÁRIO: CONFLITO, DIÁLOGO E PARTICIPAÇÃO
}

\author{
SOCIAL CONSTRUCTIONISM AND COMMUNITT WORK: \\ CONFLICT, DIALOGUE AND PARTICIPATION \\ CONSTRUCCIONISMO SOCIAL Y TRABAJO COMUNITARIO: \\ CONFLICTO, DIÁLOGO Y PARTICIPACIÓN
}

\author{
Emerson Fernando Rasera ${ }^{1}$ \\ ${ }^{1}$ Universidade Federal de Uberlândia, Uberlândia/MG, Brasil
}

RESUMO: O construcionismo social tem influenciado o desenvolvimento de variadas intervenções comunitárias. O objetivo deste estudo é descrever propostas de trabalho comunitário construcionistas e analisar o uso do discurso construcionista e os desafios enfrentados. Assim, analisamos o Projeto de Conversações Públicas, o Imagine Chicago e o Projeto da Comunidade de Cupertino. Essa análise apontou: forte ênfase no diálogo como ferramenta de mudança social; postura de coconstrução do facilitador; valorização da multiplicidade de pontos de vista; distanciamento de compromissos específicos; e busca apreciativa de corresponsabilização. Uma reflexão crítica convida ao questionamento da visão de diálogo e a valorização da dimensão política dessas práticas comunitárias.

PALAVRAS-CHAVE: Construcionismo social; Psicologia comunitária; Diálogo.

RESUMEN: El construccionismo social ha influido en el desarrollo de variadas intervenciones comunitarias. El objetivo de este estudio es describir propuestas de trabajo comunitario construccionistas y analizar el uso del discurso construccionista y los retos enfrentados. Así, analizamos el Proyecto de Conversaciones Públicas, el Imagine Chicago y el Proyecto de la Comunidad de Cupertino. Este análisis apuntó: fuerte énfasis en el diálogo como herramienta de cambio social; postura de co-construcción del facilitador; valorización de la multiplicidad de puntos de vista; distanciamiento de compromisos específicos; y una búsqueda apreciativa de corresponsabilización. Una reflexión crítica invita al cuestionamiento de la visión del diálogo y la valorización de la dimensión política de estas prácticas comunitarias.

PALABRAS CLAVE: Construccionismo social; Psicología comunitaria; Diálogo.

ABSTRACT: Social constructionism has influenced the development of various community interventions. The goal of this study is to describe constructionist community proposals and to analyze the use of the constructionist discourse and the challenges faced. Therefore, we analyzed the Public Conversations Project, Imagine Chicago and the Cupertino Community Project. This analysis showed: a strong emphasis on dialogue as a tool of social change; a stance of co-construction; the valuing of the multiplicity of points of view; distancing from specific commitments; and an appreciative search for co-responsibility. The study brings a critical reflexion that instigates the questioning of the view of dialogue and the appreciation of the political dimension of these community practices.

KEYWORDS: Social constructionism; Community psychology; Dialogue. 


\section{Introdução}

A psicologia comunitária, desde sua fundação como campo disciplinar, envolve diferentes paradigmas que orientam sua prática e pesquisa. Apesar disso, análises sobre a produção da área (Graham \& Ismail, 2011) mostram que há um predomínio de estudos empíricos, com perspectivas positivistas, sendo sub-representados estudos baseados em métodos participativos e epistemologias socialmente transformadoras. Buscando responder a essa necessidade e destacando outras perspectivas que têm emergido em áreas afins, este estudo busca analisar como o movimento do construcionismo social pode oferecer uma inteligibilidade alternativa aos profissionais envolvidos no trabalho comunitário.

O construcionismo social é um discurso contemporâneo sobre a prática psicológica, abrangendo um campo de descrições e justificativas que produzem determinados dizeres e fazeres psicológicos e sustentam uma visão de sujeito e sociedade. Esse discurso se articula por uma forte ênfase no papel da linguagem como construtora da realidade, apontando, por um lado, para seu caráter performático e, por outro, para a inserção sócio-histórica dos sistemas de significação. Trata-se de uma visão da linguagem como prática social, deslocando para um segundo plano as perspectivas representacionais da mesma. Essa ênfase redimensiona os saberes e práticas em Psicologia, privilegiando uma leitura teórico-metodológica a partir dos relacionamentos humanos (Guanaes-Lorenzi, Moscheta, CorradiWebster, \& Souza, 2014).

Enquanto discurso, não há um único construcionismo social, mas diversos construcionismos sociais, os quais estão em constante mudança. Assim, há autores que começam a apontar a existência de um pós-construcionismo, preocupado com questões de materialidade, poder e performatividade (Íñiguez, 2005), enquanto outros consideram as implicações retóricas dessa nova descrição do construcionismo social, porém reafirmam a ideia de um movimento construcionista social e concebem tais transformações como parte do processo de produção do conhecimento (Guanaes \& Rasera, 2006).

Esse discurso sobre a prática psicológica foi produzido e teve seu uso fomentado a partir de experiências em diversos campos de inserção da Psicologia, tais como a educação, as organizações de trabalho, a comunidade, a psicoterapia e a saúde (Gergen, 2001, 2011; Martins, Pellicer,\& Rasera, 2013; Souza \& Santos, 2014). A despeito de trazerem algumas ideias comuns, cada área tem desenvolvido propostas específicas compatíveis com as características e necessidades próprias. Nesse sentido, apesar de encontrarmos reflexões sistematizadoras sobre o uso do discurso construcionista em alguns campos, especialmente o da psicoterapia (Mcnamee \& Gergen, 1998) e das organizações (Hosking \& Mcnamee, 2006), não o encontramos no campo do trabalho comunitário. Faz-se importante, então, conhecermos e refletirmos sobre os trabalhos comunitários que sustentam e são sustentados por um discurso construcionista social.

No campo comunitário, foram desenvolvidas iniciativas pautadas por intervenções de solução de problemas sociais, envolvendo conflitos intergrupais, traumas coletivos, bem como modos de organização, planejamento e desenvolvimento comunitário. Essas experiências apresentam uma grande diversidade, indo desde aquelas em que há um cuidado psicoterapêutico das comunidades como no caso das práticas narrativas coletivas (Denborough, 2008), passando por aquelas experiências que usam habilidades clínicas para o trabalho em situações de conflito entre grupos na comunidade (Herzig \& Chasin, 2006) até aqueles projetos que buscam o desenvolvimento comunitário (Browne \& Jain, 2002; Spano, 2001). 
Essas intervenções desenvolveram modelos específicos de facilitação grupal e comunitária fortemente influenciados pela crença no poder transformador do diálogo e na criação de novas narrativas. Bojer, Roehl, Knuth e Magner (2011) acrescentam uma série de experiências de desenvolvimento comunitário que enfatizam ferramentas dialógicas, entre as quais podemos destacar: o Laboratório de Mudança, a Democracia Profunda, a Busca Futura e a Tecnologia de Espaço Aberto.

Hosking e Morley (2004), ao apresentarem um conjunto de trabalhos relativos ao construcionismo social no contexto comunitário, apontam algumas características partilhadas por eles: a busca de relações não hierárquicas que sustentem múltiplas realidades locais, em uma postura de abertura a novas possibilidades e de construção comum de um senso de racionalidade e moralidade; a interligação entre investigação e mudança social; o estímulo a uma polifonia de múltiplas vozes, que reconheça a diferença e estimule a participação; a centralidade de uma perspectiva apreciativa focada nos recursos; e o aspecto construtivo da linguagem, tanto por meio de perguntas que constroem novas realidades como pela escuta do outro, num entrelaçamento entre linguagem e ação.

O objetivo deste trabalho é descrever algumas propostas de trabalho comunitário consideradas construcionistas e analisar de que forma as proposições construcionistas, suas ênfases e sensibilidades, dão sustentação teórica a determinadas práticas comunitárias e quais os desafios que apresentam. Considerando esse objetivo, selecionamos para análise três propostas influentes no campo, denominadas por seus autores ou pela comunidade como construcionistas sociais, quais sejam, o Projeto de Conversações Públicas, o Imagine Chicago e o Projeto da Comunidade de Cupertino. A seleção dessas experiências se deve ao reconhecimento que elas desfrutam entre os autores construcionistas, ao caráter pioneiro e inovador de suas propostas e à grande difusão internacional que tiveram, permitindo apontar um certo modo de pensar a prática comunitária na comunidade construcionista ${ }^{1}$.

A análise dessas três propostas se orientará a partir de duas perguntas: "como descrevem o trabalho comunitário, seu objeto e mudança?” e "qual o papel do facilitador?”. Essa análise nos permitirá, então, identificar as descrições construcionistas privilegiadas em tais propostas, as semelhanças e diferenças entre as mesmas, bem como refletir sobre alguns desafios da aproximação do construcionismo ao campo da prática comunitária.

\section{O Projeto de Conversações Públicas: conflito e diálogo}

O Projeto de Conversações Públicas foi desenvolvido em Boston/Estados Unidos, em 1989, por um grupo de terapeutas familiares associados ao Instituto de Terapia Familiar de Cambridge. Havia, por parte desse grupo, o interesse em usar habilidades clínicas em contextos não clínicos (Becker, Chasin, Chasin, Herzig, \& Roth, 2013). O Projeto tinha como objetivo desenvolver e divulgar modelos conversacionais fáceis de usar em sessões de diálogos sobre questões públicas, propondo a construção do diálogo como alternativa ao debate polarizado.

A primeira iniciativa do Projeto esteve relacionada ao debate sobre o aborto nos Estados Unidos. Naquele momento, as pessoas envolvidas nessa questão estavam convivendo com níveis crescentes de hostilidade e até mesmo agressão. Foi proposto, então, um conjunto de sessões de diálogo com número variável de participantes, de único sexo ou 
misto, ativistas e não ativistas, diversas etnias, classes sociais e origens educacionais.

O modelo desenvolvido compreendia uma série de atividades, uma estrutura da sessão de diálogo e posturas a serem promovidas pelos coordenadores (Herzig \& Chasin, 2006). Por meio de contatos com a comunidade, as pessoas eram convidadas a participar do Projeto por meio de uma carta e um telefonema. Na carta, apresentavam-se o convite, os objetivos do encontro, o clima de segurança a ser promovido, bem como uma tabela comparativa entre um diálogo e um debate. A conversa telefônica servia para descrever o processo e os objetivos, bem como responder às perguntas dos potenciais participantes. Antes do início do encontro, oferecia-se um lanche coletivo que permitia às pessoas se aproximarem, porém, sem a identificação ao grupo de pertença, pois se solicitava que as pessoas não explicitassem seu posicionamento em relação ao tema do aborto. O encontro tinha como regras organizadoras: confidencialidade, respeito mútuo, liberdade em não responder, abandono do desejo de persuadir. Ele se organizava em três etapas: a) facilitadores faziam três perguntas aos participantes, em que as duas primeiras deviam ser respondidas em rodadas e a terceira seria respondida aleatoriamente; b) os participantes conversavam diretamente entre si; c) avaliação do encontro. Em relação às perguntas, a sequência era (Becker et al., 2013, pp. 267-268):

Nós gostaríamos que vocês dissessem algo sobre suas próprias experiências de vida em relação à questão do aborto. Por exemplo, algo sobre sua história pessoal relacionado a essa questão, como você passou a se interessar por ela, qual tem sido seu envolvimento.

O que está no centro da questão para você como um indivíduo?

Muitas pessoas têm dentro de sua abordagem geral em relação ao aborto algumas áreas de indefinição, alguns dilemas sobre suas próprias convicções ou até mesmo alguns conflitos dentro de si mesmas... Nós concluímos que é produtivo e útil quando as pessoas compartilham os dilemas, lutas e conflitos que possam ter em seu ponto de vista prevalecente. Nós convidamos vocês a mencionar qualquer incerteza ou certeza não muito firme, qualquer preocupação, conflitos de valor ou sentimentos mistos que vocês possam ter e desejam compartilhar.

Cada uma dessas perguntas, sua forma e momento de realização, bem como toda a estrutura da conversa se organizavam a partir de alguns orientadores, tais como preparar os participantes para uma jornada rumo ao novo, criar um contexto seguro, evitar o velho debate e fomentar a cocriação de uma nova conversação (Becker et al., 2013). Assim, na preparação dos participantes, a conversa telefônica, a carta e as orientações no início da sessão permitiriam esclarecer a natureza do encontro, descrever expectativas e realizar acordos específicos. Buscando tornar o contex to seguro, oferecia-se uma estrutura definida para a sessão, explicitava-se o papel em relação ao conteúdo e o processo, e construíam-se os participantes como coinvestigadores e os coordenadores como investigadores interessados. A tarefa de evitar o velho debate polarizado era realizada seja por meio do impedimento dos participantes de revelarem a sua posição durante o jantar, convidando-os a não olhar uns aos outros como adversários, mas como indivíduos únicos; seja pela estrutura de rodadas de pergunta e resposta e do acordo da não interrupção, pois isso impedia a reatividade e ajudava os ouvintes a evitarem o hábito de preparar repostas enquanto os outros estavam falando. Finalmente, a tentativa de fomentar a cocriação de uma nova conversação se 
dava pela proposta de diálogo alternativa ao debate com os quais eles estavam acostumados. Nessa perspectiva, o debate é entendido como a afirmação de um posicionamento de certeza, na qual se busca a defesa de suas próprias convicções, num exercício fundamental de persuasão, em que as pessoas são colocadas como representantes de um posicionamento definido pelo discurso dominante. Já o diálogo pressupõe curiosidade, complexidade, narrativa pessoal, compartilhamento de incertezas, numa relação em que se passa da oposição ao interesse, e as diferenças são entendidas como recursos sociais em potencial.

A realização de uma série desses encontros permitiu que as pessoas envolvidas, mesmo reafirmando suas opiniões sobre o tema do aborto, passassem a olhar o outro com menos hostilidade, criando assim a possibilidade de convivência entre os diferentes grupos. Essa experiência inicial foi expandida e desenvolvida junto a outros grupos e diferentes temáticas, buscando promover uma cultura do diálogo que torne possível a vida democrática. O Projeto de Conversações Públicas está ativo e utiliza essa metodologia em diferentes intervenções comunitárias.

\section{O Imagine Chicago: construindo cidades}

O projeto Imagine Chicago foi criado em 1992, em Chicago/Estados Unidos, buscando promover a imaginação e o engajamento cívico com vistas a desenvolver comunidades e a cidade como um todo. Ele foi construído como uma parceria entre líderes comunitários, educadores e jovens da cidade, em uma empreitada que valorizava o trabalho intergeracional e era fortemente influenciada pelas contribuições construcionistas da Investigação Apreciativa, tal como desenvolvida no contexto das organizações de trabalho (Browne \& Jain, 2002).

O projeto inicial consistiu de entrevistas realizadas por jovens da cidade, sobre as esperanças e os compromissos cívicos de líderes comunitários experientes. Baseado no método da Investigação Apreciativa, as entrevistas estavam organizadas numa lógica de valorização das experiências positivas vividas como forma de motivar a mudança e a construção de futuros preferíveis.

Assim, as perguntas utilizadas durante a entrevista de forma a atingir tal objetivo (Brownie \& Jain, 2002, p. 13; tradução nossa) eram formuladas da seguinte maneira:

Há quanto tempo você vive em Chicago? E nesta comunidade? (1a) O que trouxe sua família para cá? (1b) Como é para você viver nessa comunidade? (2) Quando você pensa em toda a cidade de Chicago, que lugares, pessoas ou imagens representam a cidade para você? (3) Retomando suas memórias sobre Chicago, quais foram os pontos altos para você como cidadão desta cidade? (4) Por que essas experiências significaram tanto para você? (5) Como você descreveria a qualidade de vida em Chicago hoje? (6) Quais mudanças na cidade você mais gostaria de ver? (6a) Qual você imagina que é o seu papel em ajudar fazer isso acontecer? (6b) Quem poderia trabalhar com você? (7) Feche seus olhos e imagine Chicago como você mais gostaria que ela fosse para a próxima geração. Como ela é? O que você vê e ouve? Do que você mais se orgulha de ter realizado? (8) À medida que você pensa sobre essa conversa, quais imagens se apresentam para você como capturando suas esperanças para o futuro dessa cidade? e (9) O que você 
pensa que seria um processo efetivo para ter as pessoas pela cidade conversando e trabalhando juntas para o futuro de Chicago? Quem você gostaria de trazer para uma conversa sobre Chicago?

Os resultados das entrevistas eram, então, apresentados ao público de forma a inspirar a ação coletiva e reforçar os compromissos sociais. Este projeto pioneiro envolveu quase 200 participantes e fomentou programas de formação de líderes, de melhoria da aprendizagem de crianças do ensino público e de formação de professores, entre outros.

O desenvolvimento e fortalecimento do projeto foram guiados por alguns pressupostos centrais: (a) todos os indivíduos têm uma contribuição a oferecer à vida em comunidade; (b) é possível criar organizações consoantes aos valores e que se sustentem nas habilidades dos seus participantes; (c) conectar essas organizações e indivíduos fortalece os esforços individuais; (d) a amizade serve como modelo de trabalho para o desenvolvimento da cidade. Esses pressupostos se traduziram em princípios organizadores, tais como fortalecer parcerias entre indivíduos e organizações, atuar a partir de atores motivados para a mudança, criar oportunidades para a construção de parcerias inesperadas, auxiliar indivíduos compromissados a serem agentes de mudança conectando-os com oportunidades e recursos, e manter uma visão global, criando redes intergeracionais e interculturais de indivíduos e organizações (Browne \& Jain, 2002).

De forma geral, os principais resultados do Imagine Chicago estão ligados ao reconhecimento de uma identidade compartilhada entre os participantes do Projeto, pela qual os diferentes grupos e comunidades puderam compreender as semelhanças entre suas visões sobre o futuro da cidade e serem encorajados em seus compromissos. Avaliada positivamente também foi a possibilidade criada pelo Projeto de uma parceria e responsabilidade intergeracional, que permitiu a revisão das visões uns dos outros sustentadas por jovens e adultos e a valorização da participação dos jovens no processo de mudança comunitária.

O diferencial da contribuição do Imagine Chicago nos processos de mudança comunitária está associado ao uso da Investigação Apreciativa nesse contexto, ou seja, a um modo de conversar sobre as questões comunitárias que se desloca da identificação e solução de problemas para visualização e construção coletiva de um futuro desejado a partir dos recursos existentes.

Atualmente, o projeto Imagine Chicago está associado a uma organização não governamental que desenvolve projetos comunitários com diferentes finalidades. Ele ainda desenvolveu documentos e publicações sobre métodos de promover o engajamento grupal e comunitário que têm sido utilizados em diferentes contextos (Imagine Chicago, 2009). Esse modelo de intervenção comunitária se espalhou pelo mundo, abarcando experiências em diferentes países, desde os Estados Unidos, passando pelo Chile, África do Sul, Inglaterra, Cingapura e Austrália.

\section{Projeto Cupertino: promovendo a democracia participativa}

O Projeto Cupertino foi uma proposta que visava a melhorar a qualidade do diálogo público entre moradores e gestores da comunidade de Cupertino, Califórnia, nos Estados Unidos. Ele se inseria no conjunto de esforços para a promoção de uma democracia participativa, e sustentava que para que ela se efetive é necessário o desenvolvimento de novos 
padrões de comunicação na sociedade, que potencialize a voz dos membros da comunidade e transforme os processos de tomada de decisão, redimensionando o campo político. Foi uma realização do Consórcio do Diálogo Público e, provavelmente, é a proposta de trabalho comunitário mais explicitamente comprometida com uma perspectiva construcionista entre as analisadas neste artigo.

O Projeto Cupertinho foi desenvolvido no período de 1996 a 1998, motivado pelo interesse dos membros do Consórcio do Diálogo Público em explorar como princípios da comunicação interpessoal poderiam contribuir para a promoção do diálogo público em um projeto de longa duração no contexto comunitário. A partir do contato com os gestores da cidade de Cupertino, o projeto se desenvolveu em quatro fases. Na primeira fase, o projeto buscou "dar voz às preocupações da comunidade", estimulando os moradores a expressarem seus pontos de vistas e ideias a partir de entrevistas em grupo abertas e exploratórias. A análise dos dados desses grupos revelou que o interesse mais significativo estava voltado à mudança demográfica da região, com a crescente imigração asiática e a dificuldade de conversar sobre esse tema, que foi apreciativamente denominada de "riqueza cultural" pelos facilitadores do projeto.

Na segunda fase, a comunidade foi convidada a "elicitar visões e planos de ação" relativos à "riqueza cultural" e segurança na comunidade. Essa fase se deu através de uma série de reuniões comunitárias com os residentes, bem como de entrevistas intergeracionais realizadas por estudantes de ensino médio junto a moradores idosos. Ao final dessa fase, foi realizada uma ampla reunião, na qual os resultados dos grupos e entrevistas foram apresentados. A partir desses resultados, a terceira fase buscou criar condições para que os gestores da cidade respondessem às visões, preocupações e planos dos moradores. Por meio de entrevistas com os gestores da cidade, foi criada a possibilidade de se realizar um programa de treinamento e formação de equipe para os líderes comunitários. Esse programa permitiu o treinamento para organização e desenvolvimento de diálogos públicos, bem como serviu de espaço para a definição das ações a serem realizadas pelos moradores e gestores.

$\mathrm{Na}$ última fase do projeto, buscou-se promover uma estrutura que sustentasse o processo de diálogo público. Assim, criaram-se condições que apoiassem diferentes grupos na comunidade para o desenvolvimento de planos de ação criados nas fases anteriores do projeto; foram realizados treinamentos em habilidades de comunicação por toda a comunidade; formou-se um grupo de moradores que lideraram o processo de implementação dos planos de ação, bem como se realizaram grandes eventos públicos relativos ao tema da diversidade cultural; e foi contratado um coordenador de relações comunitárias pela cidade para apoio às ações iniciadas no projeto. Esse processo permitiu que a equipe do Consórcio do Diálogo Público se afastasse e que os próprios moradores assumissem a coordenação do projeto.

A partir dessa experiência se desenvolveu um modelo do processo de diálogo comunitário, o qual possui três diferentes níveis e propõe algumas características para o desenvolvimento do diálogo público (Spano, 2001). O primeiro nível corresponde ao planejamento do processo estratégico, o qual está associado à estrutura do processo de diálogo em suas diferentes fases, contemplando diferentes eventos. O segundo nível compreende o planejamento dos eventos, os quais são realizados visando certos objetivos, e podem abranger sessões de diálogo, entrevistas em grupo, reuniões de equipe e sessões de treinamento, entre outros. O terceiro nível se refere às habilidades de facilitação da comunicação necessárias para o bom desenvolvimento dos eventos. 
O diálogo público pode ser uma ferramenta para transformar os processos de tomada de decisão à medida que cria oportunidades de debate no interior da comunidade, estimula o engajamento de seus membros e serve como meio de proposição e avaliação das ações voltadas à comunidade. O processo de tomada de decisão, a partir de uma perspectiva dialógica, deixa de se basear no debate, argumentação e persuasão rumo a ações predefinidas e se sustenta pelo exercício de exploração conjunta, de abertura à emergência das possibilidades e da deliberação situada. Esse modo de desenvolver o diálogo público exige ações de ensino e aprendizagem por parte da comunidade, pois essa forma de interação é pouco comum e contraria modos comuns de fazer política promovidos pela lógica da democracia representativa e das ações de advocacy (Spano, 2001).

No processo de diálogo público, o facilitador atua de forma a tornar possível essa forma de interagir na comunidade. No Projeto Cupertino, as ações do facilitador se orientavam a partir de uma posição de neutralidade e de não saber, ou seja, ele buscava não julgar, nem orientar os moradores em relação ao conteúdo das conversas da comunidade, ao mesmo tempo em que sustentava um interesse e curiosidade sobre as perspectivas trazidas pelos moradores em relação aos problemas e soluções. Essa postura geral se combinava com: uma orientação apreciativa, focada nos recursos para a construção do futuro, ao invés da investigação de problemas passados; a realização de um questionamento sistêmico, que explora as conexões e os relacionamentos no interior da comunidade, identificando diferentes padrões de comunicação e criando oportunidades de novas relações; e o estímulo a processos reflexivos, que aprofundam o entendimento a partir da exploração sobre os sentidos trazidos pelos participantes.

Os responsáveis pelo Projeto Cupertino destacam que as fases do projeto, as atividades realizadas e as habilidades comunicativas promovidas não oferecem uma técnica, método ou abordagem para o trabalho comunitário, mas constituem uma sensibilidade, ou "sabedoria prática" que pode inspirar outros pesquisadores e profissionais (Spano, 2001).

\section{Refletindo sobre as propostas construcionistas para a prática comunitária}

A apresentação dessas três experiências nos permite visualizar o que seria uma prática comunitária influenciada pelo construcionismo. Apesar das diferenças de objetivo, de vinculação profissional dos autores e do modelo de trabalho, é possível identificar uma mútua influência entre elas a partir da utilização de determinadas ideias. Da mesma forma, é possível reconhecer algumas ênfases características das práticas construcionistas em outros campos (Gergen \&Ness, 2016) e dos diálogos transformadores (Gergen, 2013) nas três experiências analisadas.

Assim, observamos uma forte ênfase nos processos de produção de sentidos, seja como forma de identificar o que se quer mudar (não havendo uma teoria a priori sobre o que são os problemas comunitários), seja como forma de intervenção, baseada no diálogo como ferramenta de mudança social. Esse foco na linguagem está associado a uma perspectiva que entende que determinadas formas de comunicação constroem realidades sociais. O facilitador se coloca numa postura de coconstrução junto aos grupos, convocando os participantes a colaborarem no processo compartilhado de planejamento, desenvolvimento e avaliação da intervenção na comunidade. Nesse processo, os facilitadores convocam participantes de diferentes origens na comunidade, numa postura que busca garantir 
uma multiplicidade de pontos de vista, ao mesmo tempo em que tentam se distanciar de compromissos específicos ou dos interesses de gestores públicos e partidos ou associações políticas. Da mesma forma, ultrapassam uma análise abstrata dos problemas sociais e propõem formas concretas de intervenção que contribuem para a mudança social do contex to no qual atuam, havendo um explícito propósito de transformar as realidades das quais participam. Além disso, em uma perspectiva promotora da potencialidade da comunidade, abandonam o foco na investigação diacrônica e essencialista sobre a origem do problema, em uma busca apreciativa de corresponsabilização dos sujeitos nos processos de mudança social e na construção de realidades futuras.

Essas experiências comunitárias apontam para uma alternativa a algumas visões tradicionais do trabalho neste contexto. Assim, elas abandonam ênfases na problematização ou conscientização, e os problemas decorrentes de uma visão representacional e ideológica da realidade, marcada por uma verdade exterior à comunidade, à qual ela não tem acesso e que deve ser mostrada pelo suposto saber crítico do profissional (Montenegro, 2002). A busca é pela valorização de todas as vozes da comunidade e de um questionamento do saber e da autoridade do profissional. Da mesma forma, apesar de incluir membros das camadas menos privilegiadas, o trabalho comunitário não se restringe a eles, nem se organiza a partir do entendimento de que a eles cabe a mudança social. As experiências analisadas mostram, de diferentes maneiras, como buscam envolver membros de diferentes grupos sociais, num entendimento que a transformação social deve envolver uma variedade de representantes da comunidade.

Além de reconhecer a contribuição do construcionismo para as práticas comunitárias, a análise dessas propostas nos convida a refletir sobre as possibilidades de expansão dessas práticas rumo à ampliação de seu potencial de transformação. Duas possibilidades podem ser exploradas a partir de uma reflexão sobre a visão de diálogo subjacente a essas propostas, bem como sobre a dimensão política das práticas comunitárias.

\section{Diálogo e mudança social}

As três experiências estudadas se fundamentam no diálogo como ferramenta que pode produzir variados tipos de mudanças sociais, seja o mútuo entendimento entre membros da comunidade, a promoção do engajamento cívico e do desenvolvimento da comunidade, ou a melhoria do diálogo público. De forma geral, os autores parecem partilhar de uma visão do diálogo como um tipo especial de comunicação, no qual o uso cuidadoso das palavras possibilita a abertura ao outro, a suspensão de julgamentos/preconceitos, o desenvolvimento da confiança e de uma nova forma de relacionamento entre os participantes.

Apesar de se apresentar de diferentes maneiras, e com variadas intensidades nas experiências analisadas, essa visão do diálogo está associada a alguns pressupostos e características, tais como: (a) o diálogo não é algo natural, mas algo que deve ser construído entre os participantes, e que contraria modos típicos de relacionamento em nossa sociedade atual, especialmente, em contextos públicos; (b) há uma ênfase na descrição detalhista sobre os cuidados necessários para se construir um contexto para o diálogo, o qual exige uma série de procedimentos e posturas por parte do facilitador; (c) o diálogo é valorizado como um fim em si mesmo, pautado na crença que ele pode ser parte de um processo de transformação que leva à ação; (d) tipicamente, o diálogo é diferenciado com outras formas de comunicação pautadas pelo debate, pela disputa e pela persuasão, valorizando o diálogo 
e criticando essas outras formas de comunicação; (e) há um silenciamento sobre o lugar do conflito no processo de comunicação na comunidade, que dá margem a entendê-lo, às vezes, como algo que deva ser evitado ou superado ou como algo que não é constitutivo do processo de diálogo ${ }^{2}$.

Essa forma de conceber o diálogo sugere uma visão desse como prescrição e como colaboração, ou seja, de um modo de entender o diálogo que ao atribuir um caráter especial e raro ao diálogo não explora o caráter fundamentalmente dialógico de qualquer ato comunicativo e a tensão constitutiva do encontro entre diferentes perspectivas (Stewart \& Zedicker, 2000).

Em contextos de mudança social, essa visão do diálogo como colaboração pode trazer alguns riscos, tais como: privilegiar ideias de civilidade entre as partes em detrimento de mudanças sociais efetivas; e, ao sugerir o diálogo como método superior de mudança social, acabar por promover uma desvalorização do ativismo baseado no protesto e na contraposição (Ganesh \& Zoller, 2012). Além disso, a visão do diálogo como colaboração pode sustentar uma "ideologia da harmonia" que desconsidera as relações de poder e oculta o uso do diálogo como ferramenta para apaziguamento das desigualdades e manutenção do status quo (Nader, 1991).

O enfrentamento desses riscos, talvez, possa se dar a partir da reflexão situada sobre a adequação do diálogo como ferramenta de mudança social, assumindo que ele pode ser combinado com outras estratégias. Da mesma forma, uma sensibilidade às diferenças sociais entre os participantes possa ser considerada na busca da criação de contextos de reconhecimento e transformação das relações de poder.

\section{Comunidade, politica e democracia participativa}

Analisando as propostas, observamos que a comunidade é vista como sendo composta por diferentes grupos sociais. Esses grupos podem estar vinculados a determinadas instituições, serem unidos por determinada identidade ou compartilharem uma mesma área da cidade. Há, em todos os projetos, uma visão da comunidade como abrigando diferenças que podem ser utilizadas colaborativamente na construção de realidades mais satisfatórias. As propostas analisadas se firmam a partir de uma lógica inclusiva e participativa que atribui aos participantes o poder de decisão e ação, no esforço da construção do bem comum em uma sociedade democrática.

Essas propostas desenvolvem e cuidam do que poderíamos chamar de uma "política do processo" de mudança social. Essa "política do processo" estaria marcada por: (a) forte ênfase nos processos comunicacionais, que enfatiza o modo de estar com o outro na relação imediata, porém, deixa em segundo plano a análise quer das origens sócio-históricas dos problemas identificados no trabalho comunitário, em seu desenvolvimento e resultado, quer da própria constituição dessa comunidade e sua relação com a sociedade; (b) a busca de um distanciamento dos facilitadores em relação aos temas debatidos nas intervenções (no caso de grupos em conflito) ou de compromissos políticos específicos, o que acaba criando espaço, em algumas situações, para uma suposta postura de neutralidade dos facilitadores e da intervenção proposta; e (c) há, tipicamente, pouco envolvimento do poder público na corresponsabilização sobre as ações a serem realizadas. 
Esse foco numa "política do processo" está associado a um silenciamento sobre a inserção dessas comunidades e dessas experiências no cenário político das cidades das quais fazem parte e sobre os antagonismos presentes nos projetos de mudança social. Parece haver um receio de que politizar o diálogo, para além do processo comunicacional, é empobrecê-lo. Se em algumas práticas dessas experiências há o claro reconhecimento das disputas entre os grupos, bem como a clara intenção da promoção de uma forma de participação política, em outras, esse aspecto não é explorado. Não se trata de pensar apenas a eficácia do trabalho comunitário, mas sua própria fundamentação ${ }^{3}$. Conectada a essa postura, está o pouco investimento e/ou publicização da teorização sobre o funcionamento da sociedade que sustenta as intervenções realizadas ${ }^{4}$, dificultando uma compreensão da amplitude da mudança pretendida.

Assim, por um lado, acreditamos que elas estão sintonizadas ao que Gergen (2001) propõe como uma "política das práticas relacionais", na qual a ação política deve ser difusa, envolvendo a todos em diferentes momentos, e desarmada, ou seja, menos agressiva e alienante. Por outro lado, acreditamos que aceitar o desafio de pensar as práticas comunitárias como práticas políticas, bem como analisar sua relação com programas públicos e atores políticos institucionalmente estabelecidos, pode potencializar o poder transformador dessas experiências.

Ao fazê-lo, contribui-se para reflexivamente reconhecer as restrições e as resistências ao tipo de trabalho comunitário proposto, promovendo não só a politização do comunitário e a construção de uma democracia efetivamente participativa, mas também se evitando o risco de se produzir um saber que não aponte seus próprios limites.

\section{Considerações finais}

Essa análise de três diferentes experiências de trabalho na comunidade a partir de uma perspectiva construcionista aponta a diversidade de objetivos, técnicas e formatos que elas podem vir a ter. Ela mostra como o construcionismo pode ser um campo de justificativas e de inspiração que dê sustentação e promova ações de mudança social. Trata-se de uma forma de trabalhar que não busca ou propõe que a mudança social se dá a partir de um ator social privilegiado, mas que estimula a participação de todos. Da mesma forma, ela não possui uma meta específica de transformação da sociedade, mas convida a um pluralismo de possibilidades que devem ser negociadas local e situadamente.

Uma reflexão crítica sobre a forma como o construcionismo tem se traduzido nas experiências comunitárias também aponta algumas possibilidades de expansão do seu projeto relacional. Assim, por um lado, deve-se propor formas dialógicas que incentivem a participação da comunidade na solução dos seus problemas, tal como fundamentado numa perspectiva colaborativa. Por outro lado, esse trabalho na comunidade pode ser incrementado à medida que se considere: como condições políticas e diferenças de poder podem impactar e dificultar o trabalho comunitário; outras formas de ação comunitária e sua relação com os processos dialógicos fomentados; o contexto de inserção dos projetos comunitários e seus efeitos na sociedade; e a inclusão dos gestores públicos na realização das ações, ampliando o conjunto de vozes que participam do diálogo de transformação social. 
Trata-se de um modo de pensar/fazer que vai além do construcionismo como crítica social para compreendê-lo em sua dimensão de transformação social, em uma clara combinação de teoria, análise e ação. Essa análise mostra como é possível ter um caráter crítico no trabalho comunitário a partir de uma perspectiva relativista, que não está pautada em verdades únicas ou em um sujeito político universal. Esperamos que essas reflexões contribuam com a compreensão do construcionismo social como capaz de promover a mudança social, em uma perspectiva não essencialista, e que ampliem a participação comunitária por meio de processos dialógicos.

\section{Notas}

1 A escolha por essas experiências clássicas acaba por gerar uma delimitação contextual. Dado que os Estados Unidos foram o solo de importante difusão do discurso construcionista, é compreensível que aí se localizem as experiências mais consolidadas. Contudo, considerando o objetivo do artigo, essa delimitação não produziu um viés limitante para o seu alcance. A análise da utilização das contribuições dessas experiências para o contex to brasileiro está para além do escopo deste artigo. Para o leitor interessado, é possível conhecer os trabalhos desenvolvidos por Laura Vilela e Souza, Murilo Moscheta e colaboradores (Moscheta, Souza, Casarini, \& Scorsolini-Comin, 2016; Souza, Moscheta, \& Scorsolini-Comin, 2019) e outros de nossa autoria (Rasera, 2017; Rasera, Teixeira, \& Rocha, 2014) que têm refletido sobre as possibilidades e limites do uso dessas metodologias no contexto nacional, especialmente do Projeto de Conversações Públicas.

2 Acreditamos que o conflito tenha sido experimentado em diferentes momentos dos projetos analisados; contudo, eles não são claramente discutidos na literatura produzida por seus propositores.

3 O debate político contemporâneo aponta como a busca idealizada de um consenso pode significar o fim do político (Mouffe, 1993). No campo da psicologia comunitária esse risco está presente em diferentes tradições teórico-metodológicas (Prado, 2002). Assim, vemos que os impasses da politização do diálogo não são específicos das propostas aqui analisadas e devem ainda ser enfrentados pelos interessados no tema. O aprofundamento sobre a reflexão construcionista a respeito dos desafios de perspectivas individualistas e comunitaristas subjacentes a esse debate pode se valer das análises desenvolvidas por Kenneth Gergen (2011).

4. Considerando a origem não acadêmica de duas dessas três experiências, é esperado não encontrarmos descrições epistemológicas densas sobre a prática promovida. Tipicamente, os textos produzidos consistem de narrativas situadas, relatos de experiência sensíveis e manuais que procuram disponibilizar recursos pragmáticos para sua utilização em outros contextos. 


\section{Referências}

Becker, C., Chasin, L., Chasin, R. Herzig, M., \& Roth, S. (2013). Do debate estagnado a uma nova conversação sobre questões controversas: um relato do Projeto de Conversação Pública. In D. R. Schnitman \& S. Littlejohn (Orgs.), Novos Paradigmas em Mediação (pp. 259-273). Chagrin Falls, OH: Taos Institute Publications.

Bojer, M. M., Roehl, H., Knuth, M., \& Magner, C. (2011). Mapeando diálogos. Rio de Janeiro: Instituto Noos.

Browne, B. W. \& Jain, S. (2002). Imagine Chicago. Chicago, IL: Imagine Chicago.

Denborough, D. (2008). Collective Narrative Practice. Adelaide, AUS: Dulwich Publications.

Ganesh, S. \& Zoller, H. M. (2012). Dialogue, Activism, and Democratic Social Change. Communication Theory, 22(1), 66-91.

Gergen, K. J. (2001). Social Construction in Context. Londres: Sage.

Gergen, K. J. (2011). Relational Being. Oxford, NY: Oxford University Press.

Gergen, K. J. (2013). Rumo a um vocabulário do diálogo transformador. In D. R. Schnitman \& S. Littlejohn (Orgs.), Novos Paradigmas em Mediação (pp. 29-45). Chagrin Falls, OH: Taos Institute Publications.

Gergen, K. J. \&Ness, O. (2016). Therapeutic practice as social construction. In M. O’Reilly \& J. N. Lester (Eds.), The Palgrave Handbook of Adult Mental Health (pp. 502-519). Londres: Springer.

Graham, T. M.\& Ismail, T. (2011). Content and methods trends in the Journal of Community Psychology between 2003 and 2007. Journal of Community Psychology, 39(2), 12 1-135.

Guanaes-Lorenzi, C., Moscheta, M. B., Corradi-Webster, C., \& Souza, C. V. (Orgs.). (2014). Construcionismo social. Rio de Janeiro: Instituto Noos.

Guanaes, C.\& Rasera, E. F. (2006). Therapy as social construction: an interview with Sheila McNamee. Interamerican Journal of Psychology, 4O(1), 123-132.

Herzig, M. \& Chasin, L. (2006). Fostering dialogue across divides. Watertown, MA: Public Conversations Project.

Hosking, D. \& Morley, I. E. (2004). Social constructionism in community and applied social psychology. Journal of Community and Applied Social Psychology, 14(5), 318-331.

Hosking, D. M. \& Mcnamee, S. (2006).The Social Construction of Organization. Copenhagen: Copenhagen Business School Press.

Imagine Chicago. (2009). Imagine Chicago Tools for Engagement. Recuperado dehttp://imaginechicago.org

Íñiguez, L. (2005). Nuevos debates, nuevas ideas y nuevas prácticas en la psicología social de la era 'post-construccionista'. Athenea Digital, 8, 1-7.

Martins, P. P. S., Santos, C. Pellicer, \& Rasera, E. F. (2013). A terapia focada na solução e suas aproximações ao discurso construcionista social. Estudos de Psicologia, Campinas, 30(1), 111 120. https://dx.doi.org/10.1590/S0103-166X2013000100012

Mcnamee, S. \& Gergen, K. J. (1998). A terapia como construção social. Porto Alegre: Artes Médicas. 
Montenegro, M. (2002). Ideology and community social psychology: theoretical considerations and practical implications. American Journal of Community Psychology, 30(4), 51 1-527.

Moscheta, M. S., Souza, L. V., Casarini, IK. A., \&Scorsolini-Comin, F. (2016). Da (im)possibilidade do diálogo: Projeto de Conversações Públicas e questões LGBT. Psicologia e Sociedade, 28(3), $516-525$.

Mouffe, C. (1993). The return of the political. London: Verso.

Nader, L. (1991). Harmony Ideology. Standford University Press: Standford.

Prado, M. A. M. (2002). A psicologia comunitária nas Américas: o individualismo, o comunitarismo e a exclusão do político. Psicologia: Reflexão e Crítica, 15(1), 201-210. https://dx.doi. org/10.1590/S0102-79722002000100021

Rasera, E. F. (2017). Diálogo público e trabalho comunitário: o caso do Projeto de Conversações Públicas. In M. Grandesso (Org.),Práticas colaborativas e dialógicas em distintos contextos e populações: um diálogo entre teoria e práticas (pp. 419-434). Curitiba: CRV.

Rasera, E. F., Teixeira, F. B., \& Rocha, R. M. G. (2014). Construcionismo social, comunidade e sexualidade: trabalhando com travestis. In C. Guanaes-Lorenzi, M. S. Moscheta, C. M. Corradi-Webster, \& L. V. Souza. (Orgs.), Construcionismo social: discurso, prática e produção do conhecimento (pp. 289-301). Rio de Janeiro: Instituto Noos.

Souza, L. V.\& Santos, M. A. (2014). Decisões em saúde no relacionamento entre o profissional e o paciente com transtorno alimentar. Estudos de Psicologia, (Campinas), 31(1), 75-84. https:// dx.doi.org/10.1590/0103-166X2014000100008

Souza, L. V., Moscheta, M. S., \& Scorsolini-Comin, F. (2019). Public Conversations Group as Resource Against LGBT Violence. Paidéia,(Ribeirão Preto), 29, e2905. Epub February 04, 2019.https://dx.doi.org/10.1590/1982-4327e2905

Spano, S. (2001). Public Dialogue and Participatory Democracy: The Cupertino Community Project. Cresskill, NJ: Hampton Press.

Stewart, J.\& Zediker, K. (2000). Dialogue as tensional, ethical practice. Southern Communication Journal, 65(2-3), 224-242.

\section{Agradecimentos}

À Coordenação de Aperfeiçoamento de Pessoal de Nível Superior (Processo BEX: 6384/10-2) e ao Conselho Nacional de Desenvolvimento Científico e Tecnológico (Bolsa PQ) pelo apoio financeiro; e à professora Sheila Mcnamee pelas interlocuções que motivaram e amadureceram o desenvolvimento do projeto de pós-doutorado na Universidade de New Hampshire (EUA), do qual este artigo é resultado. 


\section{EMERSON FERNANDO RASERA}

http://orcid.org/0000-0001-6289-2313

Mestre e doutor em Psicologia pela Universidade de São Paulo (2000, 2004), e pós-doutorado pela University of New Hampshire (EUA) (2011-2012). Atualmente é professor associado IV da Universidade Federal de Uberlândia e docente do Programa de Pós-graduação em Psicologia. Líder do Grupo de Pesquisa "Psicologia, Saúde e Construcionismo Social" (CNPQ). Desenvolve ações de cooperação com a University of New Hampshire (EUA) e NHTV Breda University of Applied Sciences (Holanda).

Endereço: Av. Pará, 1720, Bloco 2C, Uberlândia/MG, Brasil. CEP 38405-318.

Email: emersonrasera@gmail.com

\begin{tabular}{|l|l|}
\hline \multirow{2}{*}{ Histórico } & $\begin{array}{l}\text { Submissão: 08/02/ } 2019 \\
\text { Revisão: 09/12/2019 } \\
\text { Aceite: 12/02/2019 }\end{array}$ \\
\hline Financiamento & $\begin{array}{l}\text { Coordenac̃ão de Aperfeiçoamento de Pessoal de Nível } \\
\text { Superior (Processo BEX: 6384/10-2) e Conselho Nacional } \\
\text { de Desenvolvimento Científico e Tecnológico - Bolsa PQ }\end{array}$ \\
\hline
\end{tabular}

